Diterima Redaksi: 24-01-2022 | Selesai Revisi: 13-02-2022 | Diterbitkan Online: 22-02-2022

\title{
Penyajian Laporan Keuangan Entitas Berorientasi Nonlaba Berdasarkan ISAK 35 Di Gereja HKBP Pangaribuan
}

\author{
Sahala Purba ${ }^{1}$, Deby Tobing ${ }^{2 *}$, Hizkia Tambunan ${ }^{3}$, Leni Siagian $^{4}$, Rejeki Elmawati $^{5}$ \\ 1,2,3,4,5 Prodi Akuntansi, Fakultas Ekonomi, Universitas Methodist Indonesia, Medan, Indonesia \\ Email: sahala824@gmail.com ${ }^{1}$, debytobing08@ gmail.com ${ }^{2}$, hjktambunan@gmail.com ${ }^{3}$ \\ leninataliasiagian@gmail.com ${ }^{4}$, rejekielma21@gmail.com ${ }^{5}$
}

\begin{abstract}
The church as a non-profit oriented entity financially accepts donations from the congregation/ congregation to fund its ministry activities. Legitimacy theory can be used to explain the position of the church as an entity that has a social contract with the people, namely how the church in this case the church manager can provide services church that grows and maintains the faith and belief of the people through all its activities. Non-profit financial reporting is regulated by ISAK 35. Interested parties will be able to assess the church's financial performance with the implementation of ISAK 35. The HKBP Pangaribuan Church is the object of this research. interviews and observations were conducted to collect data. So far, the Pangaribuan HKBP Church has only made reports on cash in and cash out. This study aims to describe the financial statements of the HKBP Pangaribuan Church with financial reports based on ISAK 35 by using an auxiliary application, namely MS. Excel. In short, non-profit organizations are different from business entities. Although non-profit organizations do not focus on making profit, they still face financial problems because non-profit organizations have budgets, pay employees, pay bills, electricity and telephone and others. The church is a non-profit organization that is a place of worship for Christians. The church is also used as a place to study the Bible and of course to study religion.
\end{abstract}

Keywords: Church, Financial Report, ISAK 35

\begin{abstract}
Abstrak
Gereja sebagai salah satu entitas berorientasi nonlaba secara finansial menerima sumbangan dari umat/jemaat untuk mendanai akvitas pelayannya. Teori legitimasi dapat digunakan untuk menjelaskan posisi gereja sebagai suatu entitas yang memiliki kontrak sosial dengan umat, yaitu bagaimana gereja dalam hal ini pengelola gereja dapat memberikan pelayanan gerejani yang menumbuhkan dan memelihara iman dan kepercayaan umat melalui seluruh aktivitasnya. Pelaporan keuangan nonlaba diatur oleh ISAK 35. Para pihak yang berkepentingan akan bisa melakukan penilaian kinerja keuangan gereja dengan diterapkannya ISAK 35. Gereja HKBP Pangaribuan meruapakan objek pada penelitian ini. wawancara dan observasidilakukan untuk mengumpulkan data. Sejauh ini Gereja HKBP Pangaribuan masih hanya membuat laporan sebatas kas masuk dan kas keluar saja. Penelitian ini bertujuan untuk menggambarkan laporan keuangan Gereja HKBP Pangaribuan dengan laporan keuangan berdasarkan ISAK 35 dengan menggunakan aplikasi pembantu yaitu MS. Excel. Singkatnya, organisasi non laba berbeda dengan badan usaha. Meskipun organisasi non laba tidak fokus mencari keuntungan, namun masih menghadapi masalah keuangan karena organisasi non laba memiliki anggaran, membayar karyawan, membayar tagihan, listrik dan telepon dan lainnya. Gereja adalah organisasi nirlaba yang menjadi tempat peribadatan umat Kristiani. Gereja juga digunakan sebagai tempat untuk belajar Alkitab dan tentunya untuk belajar ilmu agama.
\end{abstract}

Kata Kunci : Gereja, Laporan Keuangan, ISAK 35 


\section{A. PENDahuluan}

Organisasi non laba termasuk organisasi keagamaan, rumah sakit, sekolah umum, dan organisasi sukarelawan. Organisasi non laba menjadikan sumber daya manusia sebagai aset yang paling berharga, karena semua aktivitas organisasi pada dasarnya adalah dari, oleh dan untuk manusia. Sejak tahun 1997, pelaporan keuangan organisasi non laba telah diatur oleh PSAK 45. Dan pada tahun 2019, PSAK 45 telah diganti dengan ISAK 35. Dengan diterbitkannya peraturan baru ini, organisasi non laba diwajibkan untuk menyajikan laporan keuangannya. sesuai dengan ISAK 35.

Gereja HKBP (Huria Kristen Batak Protestan) tumbuh dari misi lembaga misionaris RMG (Rheinische Missionsgesellschaft) dari Jerman dan Belanda melalui misionaris Pdt Heine, Pdt Klemmer, Pdt Betz dan Pdt Van Asselt. Pada tanggal 7 Oktober 1861, wilayah penginjilan baru dibuka untuk Sumatera, di negara Bataklanden atau Batak. Gereja ini setiap minggu gereja ini menerbitkan laporan pendapatan dan pengeluaran terperinci dari setiap kolom. Pembukuan tahunan gereja hanya terdiri dari pendapatan, pengeluaran, anggaran dan realisasi, pelaporan keuangan semacam ini baik di gereja tetapi sering terjadi ketegangan yang disebabkan oleh pelaporan keuangan ini. Oleh karena itu, untuk memberikan pelaporan keuangan yang jelas, keuangan gereja harus dapat menerapkan laporan keuangan berdasarkan PSAK No. 45 .

Tujuan dari penelitian ini adalah untuk mengetahui bagaimana penerapan laporan keuangan Gereja HKBP Bukit Pangaribuan sudah sesuai dengan Interpretasi Standar Akuntansi Keuangan (ISAK) 35.

\section{B. PELAKSANAAN Dan Metode}

Jenis penelitian ini adalah penelitian kualitatif dengan pendekatan analisis deskriptif. Penulis melakukan penelitian dengan menggunakan metode pengumpulan data untuk memperoleh data yang dibutuhkan yaitu: a. Tinjauan Literatur

b. Wawancara

c. Observasi

\section{Metode Analisis Data}

a. Primer Metode analisis data primer ini dilakukan dengan mengunjungi pihak entitas.

b. Sekunder Peninjauan lapangan dilakukan dengan cara mengunjungi langsung ke Gereja HKBP Pangaribuan untuk mengumpulkan data yang diperlukan dalam penelitian.

\section{HASIL DAN PEMBAHASAN}

1. Laporan Penghasilan Komprehensif

Laporan komprehensif dapat kita lihat pada kolom Perubahan aktiva bersih penambahan setiap aktiva bersih pada akhir periode. Namun pada bulan Oktober 2021, kekayaan bersih Gereja HKBP Pangaribuan keseluruhan mengalami penurunan yang dapat dilihat pada kolom Total Pendapatan Komprehensif. Pada awal Oktober 2021, total harta bersih adalah Rp 110.000.000, sedangkan pada akhir Oktober 2021, total aset bersih turun menjadi Rp 100.030.000.

Gereja HKBP Pangaribuan Laporan Komprehensif untuk periode yang berakhir bulan Oktober 2021

$\begin{array}{lcc}\begin{array}{l}\text { Tanpa pembatasan dari pemberi sumber daya Pendapatan tanpa } \\ \text { pembatasan }\end{array} & & \\ \text { sumbangan Gereja } & \text { TP } & 4.500 .000 \\ \text { pendapatan Investasi jangka panjang gereja } & \text { TP } & 6.000 .000 \\ \text { pendapatan Investasi jangka pendek gereja } & \text { TP } & 3.300 .000 \\ \text { pendapatan pembayaran Iuaran gereja } & \text { TP } & 4.800 .000\end{array}$


pendapatan persembahan Tahunan gereja

pendapatan bagi hasil gereja

Total pendapatan tanpa pembatasan

Beban-beban

beban tanpa pembatasan

beban gaji Pendeta

beban gaji biblevrow

beban gaji Guru huria

beban pensiunan penatua gereja

beban transportasi pendeta

beban petugas kebersihan

beban air

beban listrik

beban fotocopy

beban Loundry

beban operasional gereja

beban rapat (pendeta danpenatua gereja)

bebaan administrasi khas bank gereja

Total Beban Tanpa Pembatasan

Surplus tanpa pembatasan

Dengan Pembatasan dari pemberi sumber daya

Pendapatan dengan pembatasan

sumbangan anak Yatim

Pendapatan sumbangan panti jonpo

pendapatan bagi hasil fakir miskin

pendapatan bagi hasil anak yatim

Pendapatan sumbangan remaja gereja

pendapatan sumbangan anak sekolah minggu

Total pendapatan dengan pembatasan

Total Pendapatan

Beban dengan pembatasan

beban anak yatim

beban panti jompo

beban fakir miskin

beban remaja gereja
TP $\quad 3.000 .000$

TP 2.500 .000

24.100 .000

TP

$\mathrm{TP}$

TP $\quad 6.000 .000$

TP $\quad 3.500 .000$

TP $\quad 4.000 .000$

TP $\quad 1.500 .000$

TP 700.000

TP $\quad 800.000$

TP $\quad 250.000$

TP $\quad 300.000$

TP 300.000

TP $\quad 420.000$

TP $\quad 1.500 .000$

TP $\quad 1.000 .000$

TP 300.000

20.570 .000

3.530.000

DP

DP $\quad 5.500 .000$

DP $\quad 5.500 .000$

DP $\quad 5.000 .000$

DP 600.000

DP $\quad 3.500 .000$

DP $\quad 3.000 .000$

23.100 .000

47.200 .000

DP $\quad 6.000 .000$

DP $\quad 6.000 .000$

DP $\quad 2.500 .000$

DP $\quad 2.000 .000$ 
beban anak sekolah minggu

\begin{tabular}{ll} 
DP & 2.000 .000 \\
DP & 300.000 \\
DP & 300.000 \\
DP & 2.000 .000 \\
DP & 750.000 \\
DP & 600.000 \\
\hline DP & 400.000 \\
\hline DP & 500.000 \\
& 600.000 \\
& 800.000 \\
& 600.000 \\
& 500.000 \\
& 400.000 \\
& 750.000 \\
& 600.000 \\
& 27.600 .000 \\
& $\mathbf{4 8 . 1 7 0 . 0 0 0}$ \\
& $\mathbf{4 . 5 0 0 . 0 0 0}$ \\
& 0 \\
\hline
\end{tabular}

beban administrasi kas anak yatim

beban administrasi kas panti jompo

beban konsumsi

beban penyusutan peralatan sekolah minggu

beban perlengkapa ngedung sekolah minggu

beban petugas kebersihan gedung sekolah minggu

beban penyusutan banguan gedung S.minggu

beban penyusutan bangunan gedung S.guna gereja

$-970.000$

Total penghasilan komprehensif

Gambar 1. Penghasilan Komprehensif Sumber: Gereja HKBP Pangaribuan

\section{Laporan perubahan Harta bersih}

Laporan perubahan Harta bersih mencantumkan Informasi Harta bersih tanpa pembatasan dari pemberi sumber daya dan juga asset neto dan juga Harta bersih dengan pembatasan dari pemberi sumber daya.

Dalam hal terjadi perubahan aktiva bersih terdapat dua aktiva bersih yaitu aktiva bersih tanpa aktiva bersih dan aktiva bersih dengan. Laporan ini mengidentifikasi kelebihan informasi atau defisit kekayaan bersih untuk jangka waktu tertentu. Berikut laporan perubahan kekayaan bersih Gereja HKBP Pangaribuan Oktober 2021:

Gereja HKBP Pangaribuan Laporan Perubahan HARTA BERSIH Untuk Periode Yang Berakhir Bulan januari 2021

harta bersih Tanpa Pembatasan Dari Pemberi Sumber

daya

Saldo Awal

Surplus (Defisit)Tahun berjalan 
Saldo Akhir

$$
53.530 .000
$$

Harta bersih Dengan Pembatasan Dari Pemberi Sumber Daya

Saldo Awal 51.000 .000

Defisit Tahun berjalan $-4.500 .000$

Saldo Akhir 46.500 .000

\section{TOTAL HARTA BERSIH}

\subsubsection{0}

Gambar 2. Laporan Perubahan Harta bersih Sumber : Gereja HKBP Pangaribuan

\section{Laporan Posisi Keuangan}

Menjelaskan mengenai posisi aset, liabilitas dan aset bersih pada waktu tertentu adalah laporan posisi keuangan. Laporan keuangan organisasi non laba dapat dijelaskan dibawah ini:

a) Aset

b) Liabilitas

c) Harta bersih

1) Harta bersih Tanpa Pembatasan (without restrictions)

2) Harta bersih Dengan Pembatasan (with restrictions)

Dalam neraca terdapat nilai akhir perbendaharaan gereja, total aset gereja, serta kewajiban-kewajiban yang harus dipikul oleh gereja. Untuk saldo akhir kekayaan bersih, akan diambil nilai laporan laba rugi komprehensif yang mengalami kenaikan atau penurunan. Meninjau kembali laporan situasi keuangan Gereja HKBP Pangaribuan Oktober 2021.

\section{Gereja HKBP Pangaribuan Laporan Posisi Keuangan per 31 Oktober 2021}

\section{ASET /Aset Lancar}

Kas dan setara kas

perlengkapan gedung sekolah minngu

Perlengkapan Gereja

perlengkapan gedung serbaguna gereja

\section{Total Aset Lancar}

\section{ASET TIDAK LANCAR}

Tanah

Bangunan Gereja

Akumulasi penyusutan bangunan gereja

Bangunan gedung sekolah minggu

\subsubsection{0}

880.000

2.200 .000

1.100 .000

22.580.000

20.000.000

$-750.000$

2.000 .000 
Akumulasi penyusutan gedung sekolah minggu

Bangunan Gedung serbaguna gereja

Akumulasi penyusutan gedung serbaguna gereja

Peralatan Gereja

Akumulasi penyusutan Peralatan Gereja

Peralatan gedung sekolah minggu

Akumulasi penyusutan peralatan gedung sekolah minggu

Peralatan Gedung serba guna gereja

Akumulasi penyusutan peralatan gedung serbaguna gereja

\section{Total Aset Tidak Lancar}

Total Aset

Total Liabilitas

Harta bersih

Harta bersih Tanpa Pembatasan

Harta bersih Dengan Pembatasan

Total Harta bersih

Total Liabilitas Dan Harta bersih
$-750.000$

7.000 .000

$-750.000$

600.000

$-350.000$

500.000

Gambar 3. Laporan Posisi Keuangan Sumber : Gereja HKBP Pangaribuan

\section{Laporan Arus Kas}

Laporan arus kas menyajikan aktifitas operasional, aktivitas investasi dan aktifitas pendanaan dimuat dalam laporan arus kas.

Laporan arus kas menunjukkan kas masuk dan kas keluar saja, jika terjadi salah catat maka maka saldo kas tidak sama dengan yang ada di laporan posisi keuangan. Berikut laporan arus kas Gereja HKBP Pangaribuan pada Oktober 2021:

Gereja HKBP Pangaribuan Laporan arus kas untuk periode yang berakhir bula Oktober 2021 (di sajikan dalam bentuk rupiah)

\section{Aktivitas Operasi}

penyesuaian surplus (defisit)manjadi kas bersih datri aktifitas operasi:

Perubahan dalam harta bersih 
penyesuaian untuk rekonsiliasi untuk harta bersih menjadi kas bersih yang digunakan untuk aktifitas operasi :

Ditambah :

beban penyusutan peralatan gereja

beban penyusutan peralatan gedung sekolah minggu

beban penyusutan peralatan gedung serbaguna

800.000

beban penyusutan bangunan gereja

400.000

beban penyusutan bangunan gedung sekolah minggu

500.000

beban penyusutan bangunan gedung serbaguna

600.000

penurunan perlengkapan gereja

600.000

penurunan perlengkapan gedung sekolah minggu

600.000

penurunan perlengkapan gedung serbaguna

600.000

Kas bersih yang diterima (digunakan) untuk 4.630.000 aktifitas investasi

Aktivitas Investasi

kas neto yang di terima (digunakan)untuk aktifitas pendanaan

\section{Aktifitas pendanaan}

Kenaikan atau penurunan harta bersih dalam kas dan setara kas

4.630.000

kas pada awal bulan

13.770.000

kas pada akhir bulan

Gambar 4. Laporan Arus Kas Sumber : Gereja HKBP Pangaribuan

\section{Catatan Atas Laporan Keuangan}

Catatan atas laporan keuangan memuat penjelasan pos-pos laporan keuangan, gambaran umum Gereja dan ikhtisar kebijakan akuntansi.

\section{Neraca Saldo Setelah Penutupan}

Neraca Saldo setelah penutupan merupakan neraca awal untuk periode yang akan datang. Berikut neraca saldo periode Oktober 2021 untuk digunakansebagai neraca saldo awal periode pada November 2021 : 


\section{Harta}

\section{Harta lancar}

kas \& setara kas

18.400 .000

Perlengkapan Gereja

2.200 .000

Perlengkapan Gedung sekolah minggu

880.000

Perlengkapan Gedung serbaguna gereja

1.100 .000

\section{Aset Tidak lancar}

Tanah

50.000 .000

Bangunan Gereja

20.000 .000

Akm.Penyusutan bangunan gereja

Bangunan gedung sekolah minggu

2.000 .000

Akm.Penyusutan gedung sekolah minggu

Bangunan gedung serbaguna

7.000 .000

Akm.penyusutan gedung serbaguna gereja

peralatan gereja

600.000

Akm.peralatan gereja

peralatan gedung sekolah minggu

500.000

Akm.peralatan gedung sekolah minggu

peralatan gedung serba guna

700.000

Akm.peralatan gedung serbaguna

Harta bersih Dengan Pembatasan

\section{KEWAJIBAN}

\section{Harta Bersih}

Harta bersih Tanpa Pembatasan

53.530 .000

Harta Bersih Dengan Pembatasan

46.500.000

\section{TOTAL}

Gambar 5. Neraca Saldo Setelah Penutupan Sumber : Gereja HKBP Pangaribuan

\section{PENUTUP}

\section{Simpulan}

Berdasarkan hasil penelitian tersebut, maka peneliti menyimpulkan bahwa:

1. Kenaikan dan penurunan harta bersih dilihat pada penyusunan Laporan Penghasilan Komprehensif, kewajiban, nilai dari aset serta aset Gereja HKBP Pangaribuan per 30 September dan 31 Oktober diperlihatkan pada laporan posisi keuangan pada HKBP Pangaribuan diperlihatkan pada Laporan Arus Kas. 
2. Pencatatan Keuangan Gereja HKBP Pangaribuan menggunakan Metode yang sederhana. Pencatatan keuangan hanya dilakukan jika terjadi kas masuk dan kas keluar atau basis kas. Kemudian jumlah kas masuk,kas keluar dan total kas dilaporkan setiap Hari Minggu dengan cara disampaikan menggunakan Microphone Gereja.

3. Penyusunan Laporan Keuangan Gereja HKBP Pangaribuan yang disusun berdasarkan ISAK 35 menghasilkan laporan keuangan yang lebih terstruktur dan lebih terperinci bukan hanya terkait kas masuk dan kas keluar semata.

\section{Saran}

Dengan dilakukan nya penelitian dan penyajian Laporan Keuangan entitas nirlaba menggunakan ISAK No. 35 ini peneliti berharap entitas nirlaba khususnya Gereja HKBP Pangaribuan menetapkan ISAK No 35 untuk kedepan nya agar pelaporan keuangan nya lebih terstruktur dan lebih terperinci dan dengan adanya penelitian ini kita bisa melihat bagaimana laporan posisi keuangan Gereja yang sebenarnya.

\section{E. DAFTAR PUSTAKA}

Bastian, Indra. 2007. Akuntansi Yayasan Dan Lembaga Publik. Jakarta: PT Erlangga

Diviana,Sukma.(2020). Penyajian Laporan keuangan entitas berorientasi nonlaba berdasarkan ISAK 35 pada masjid Baitul Haadi. Jurnal Akuntansi dan Manajemen.

Halim Abdul, Muhammad Syam Kusufi. 2013. Teori, Konsep, dan Aplikasi Akuntansi Sektor Publik. Jakarta: Salemba Empat.

Harahap, Sofyan Syafri. 2007. Teori Akuntansi, edisi revisi 09, Jakarta: PT Raja Grafindo Persada, Jakarta Ikatan Akuntan Indonesia. 2011. Standar Akuntansi Keuangan Entitas Tanpa Akuntabilitas Publik. Jakarta. Ikatan Akuntan Indonesia. 2011. Pernyataan Standar Akuntansi Keuangan Nomor 109. Jakarta: IAI

Ikatan Akuntan Indonesia. 2017. Standar Akuntansi Keuangan per 1 Januari 2017. Jakarta.

Ikatan Akuntan Indonesia, 2016. Standar Akuntansi Keuangan per 1 Januari 2016. Jakarta.

Ikatan Akuntan Indonesia. 2018. Pedoman Akuntansi Keuangan. Jakarta.

Ikatan Akuntan Indonesia. (2018). Draft Eksposur Pernyataan Standar Akuntansi Keuangan (DE PSAK) 112 tentang Akuntansi Wakaf

Maulana,S.I.(2021).Penerapan ISAK No 35 tentang penyajian laporan keuangan entitas berorientasi nonlaba pada masjid besar AL-Atqiyah kecamatan Moyo utara kabupaten Sumbawa.Jurnal of Accounting,Finance, and Auditing.

Rudianto. 2012. Pengantar Akuntansi Konsep dan Teknik Penyusunan Laporan Keuangan. Jakarta: Erlangga.

SAK Ikatan Akuntan Indonesia Online. ISAK 35. Penyajian Laporan Keuangan Entitas Berorientasi Nonlaba per 1 Januari 2020. Jakarta.

S.R, Soemarso. 2009. Akuntansi Suatu Pengantar Buku 1 Edisi 5. Jakarta: Salemba Empat.

Syahadatina, Rika (2017). Akuntabilitas pengelolaan alokasi dana desa di desa Rapa Laok kecamatan Omben kabupaten Sampang.Aktiva jurnal Akuntansi.

Warrent, dkk. 2017. Pengantar Akuntansi Adaptasi Indonesia. Edisi 25. Jakarta: Salemba Empat. 